OPEN ACCESS

Edited by:

Xiaodong Fu,

Institute of Rock and Soil Mechanics

(CAS), China

Reviewed by:

Fengqiang Gong,

Southeast University, China

Mingzhong Gao,

Sichuan University, China

*Correspondence:

Xiaohui Liu

liuxh@mail.xhu.edu.cn

Specialty section:

This article was submitted to Geohazards and Georisks,

a section of the journal

Frontiers in Earth Science

Received: 10 November 2021 Accepted: 22 December 2021

Published: 02 February 2022

Citation:

Liu X, Xue Y, Zheng Y and Li H (2022) Research on Failure Precursor Based on Characteristics of Energy Dissipation Rate for Rock.

Front. Earth Sci. 9:812438.

doi: 10.3389/feart.2021.812438

\section{Research on Failure Precursor Based on Characteristics of Energy Dissipation Rate for Rock}

\author{
Xiaohui Liu ${ }^{1,2,3 *}$, Yang Xue ${ }^{1,2}$, Yu Zheng ${ }^{1,2}$ and Hongying $\mathrm{Li}^{1,2}$ \\ ${ }^{1}$ Key Laboratory of Fluid and Power Machinery, Ministry of Education, Xihua University, Chengdu, China, ${ }^{2}$ School of Energy and \\ Power Engineering, Xihua University, Chengdu, China, ${ }^{3}$ Key Laboratory of Deep Earth Science and Engineering, Ministry of \\ Education, Sichuan University, Chengdu, China
}

Research on early warning of rock disaster based on the energy theory is closer to the essence of rock failure. In this paper, static compression tests and acoustic emission (AE) tests of coal rock under $0,8,16$, and $25 \mathrm{MPa}$ confining pressures were carried out on the MTS815 test system. Energy evolution law in the rock failure process was analyzed according to the relationship between mechanical parameters, $A E$ parameters, and energy dissipation rate (EDR) in the rock failure process. Eventually, a new index for evaluating rock failure precursors was proposed based on EDR. The results show that the EDR has a good correlation with mechanical strength and $A E$ events under different confining pressures. The deformation and failure characteristics of coal rock can be truly characterized by EDR. The variation of EDR can be divided into a quiet stage, a stable increasing stage, an active stage, and a stable stage. The EDR level in the quiet stage is obviously enhanced by confining pressure. When EDR reaches the peak, AE events increase rapidly. In the active stage, the EDR peak value is concentrated and large, the AE event is highly active, and stress drops abruptly, indicating that the EDR is reliable for evaluating the rock failure process. Compared with AE test results, it is found that the warning stress and warning time of the EDR failure precursor occur later than that of the AE failure precursor, and the former is closer to the peak stress of rock, which is more universal in engineering and could provide a better reference value for preventing rock disaster.

Keywords: energy dissipation rate, confining pressure, failure precursor, acoustic emission, evolution of rock failure

\section{INTRODUCTION}

The research on early warning of rock disaster has been of concern to many scholars. As common catastrophic accidents in underground engineering (such as mining, tunnel, and water conservancy engineering), rock burst and large deformation of soft rock not only cause significant property losses, but also pose a serious threat to the safety and productivity of underground projects (Jiang et al., 2017; Zhang et al., 2017). In terms of engineering practice, drilling method (Qin et al., 2019), infrared radiation, electromagnetic radiation (Tian et al., 2016; Zhou et al., 2019; Zhou C. H. et al., 2020), microseism (Cai et al., 2014; He et al., 2017; Wang et al., 2021), and other early warning monitoring methods have been widely used in underground engineering, playing an important role in disaster early warning. However, most of them are present in existing projects, and all come from the site 
TABLE 1 | X-ray fluorescence analysis of coal and rock.

\begin{tabular}{lcccc}
\hline Coal sample & \multicolumn{5}{c}{ The sample element content (\%) } \\
\hline Furong Baijiao Coal & $\mathrm{C}$ & $\mathrm{O}$ & $\mathrm{Si}$ & $\mathrm{Ca}$ \\
& 73.7964 & 16.2287 & 4.6982 & 2.3815 \\
& $\mathrm{Al}$ & $\mathrm{S}$ & $\mathrm{Fe}$ & $\mathrm{Cl}$ \\
& 1.0512 & 0.8656 & 0.6790 & 0.0711 \\
$\mathrm{~K}$ & $\mathrm{Na}$ & $\mathrm{Mn}$ & $\mathrm{Ti}$ \\
& 0.0876 & 0.0335 & 0.0400 & 0.0506 \\
$\mathrm{Sr}$ & $\mathrm{Cr}$ & $\mathrm{Co}$ & $\mathrm{Br}$ \\
& 0.0074 & 0.0037 & 0.0027 & 0.0028
\end{tabular}

monitoring and conceptual model of the project. How to reveal the mechanism of rock disaster, how to prevent rock disaster in advance, and how to optimize the measures of prevention and control should be based on experimental research and engineering numerical simulation.

In laboratory tests, the characteristics of rock failure precursors can be discussed from a macrocosm and a microcosm point of view. In the macroscopic aspect, failure precursor characteristics of stress, strain, and macro-failure morphology are analyzed, while energy, crack (Gao et al., 2021a; Gao et al., 2021b), infrared thermal image, acoustic emission, and other auxiliary means are used in the microscopic aspect. Among them, acoustic emission (AE) monitoring can be used to evaluate rock damage by detecting the location, direction, and size of $\mathrm{AE}$ sources during rock deformation and failure (Liu et al., 2014; Du et al., 2020; Yang et al., 2020). It is one of the most commonly used indoor test methods to realize the guidance of indoor test to the engineering field. Through research, it is found that the abrupt change of $\mathrm{AE}$ time series parameter or AE accumulative parameter before rock failure can be regarded as the precursor character of rock failure (Li et al., 2016; Liu et al., 2020a). Zhao found that the minimum frequency centroid of an acoustic emission signal can serve as a precursor to rock failure (Zhao et al., 2020a). The quiet period of acoustic emission before rock failure can also indicate that rock failure is imminent (Ai et al., 2011; Guo and Wong, 2020). However, in contrast to actual project monitoring, the researchers found that the quiet period of acoustic emission from coal rock prior to a gas or rock burst did not correlate well with the time of the disaster (Li et al., 2019). Therefore, there are some limits in the prediction of failure precursors by acoustic emission, and the prediction methods of rock failure precursors need to be further studied.

It is worth mentioning that the essence of rock disaster is that the rapid release of elastic energy in rock leads to the instability and failure of rock. As the core driving force of rock failure, energy can better combine theory with engineering practice (Xie et al., 2008). It is more universal to explain the failure mechanism of rock in terms of energy. Research shows that the energy characteristics of rock deformation and failure vary with the storage environment (Li et al., 2014; Zhao et al., 2015; Junthong et al., 2019; Zhou Z. et al., 2020; Ma et al., 2021). Research shows that the energy characteristics of rock deformation and failure vary with the storage environment (Si and Gong, 2020; Xie et al.,

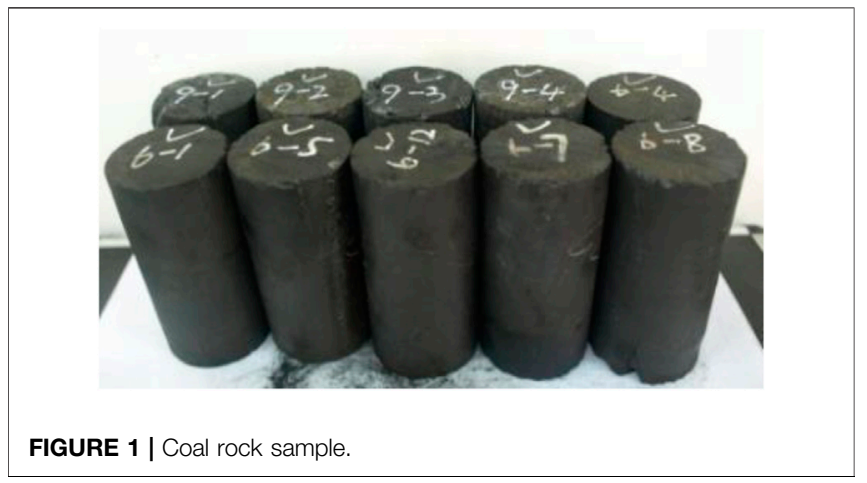

2021). Xie revealed the failure mechanism of rock from the energy point of view and established the strength and failure criterion of rock based on the energy theory (Xie et al., 2005). Based on energy theory, many scientists have established predictive indicators of rock hazard strength grades, such as the peak strength strain energy index (Gong et al., 2019), impact energy index (Yaodong et al., 2011), index of residual elastic properties (Gong et al., 2021), and failure strength index (Gao et al., 2020). However, these indicators cannot meet the requirements of early warning. In the study of energy failure precursors, Hou proposed that took the abrupt point of elastic-loss ratio as the precursor point of rock failure (Hou et al., 2021). Based on energy dissipation and energy release, $\mathrm{Xu}$ established a model for predicting rock failure cusp catastrophe, which can be used to predict rock failure precursors from an energy perspective (Xu et al., 2020). However, the study of rock energy mainly focuses on the total energy or the energy at peak stress, and the qualitative analysis of energy evolution in the rock failure process is emphasized. There are few studies on the law of energy changing with time, and the prediction of energy destruction is not deep enough.

In this paper, static compression tests and acoustic emission location test (AE) for coal rocks are carried out based on the MTS rock mechanics test system under different confining pressures. Focusing on the mechanical properties and acoustic emission characteristics of rocks under different confining pressures, energy evolution law in the process of rock deformation and failure is discussed, and the characteristics of energy dissipation rate are further emphasized. Finally, the prediction method of rock failure precursor based on energy dissipation rate is proposed, and its applicability and accuracy are verified by acoustic emission failure precursor.

\section{EXPERIMENTAL THEORY}

\section{Sample Preparation and Test Plan}

Coal rocks from Furong Baijiao coal mine in Sichuan, China were used in the test. The main mineral compositions of coal samples were determined as $\mathrm{SiO}_{2}$ and $\mathrm{AlPO}_{4}$ determined by X'Pert Pro MPD diffractometer. The contents of elements in coal and rock were analyzed by $\mathrm{x}$-ray fluorescence, as shown in Table $\mathbf{1}$. The 
TABLE 2 | Basic characteristics of coal rock samples.

\begin{tabular}{|c|c|c|c|c|c|c|c|}
\hline Serial number & $\begin{array}{c}\text { Confining } \\
\text { pressure/MPa }\end{array}$ & $\begin{array}{c}\text { Diameter/ } \\
\mathrm{mm}\end{array}$ & $\begin{array}{l}\text { Height/ } \\
\text { mm }\end{array}$ & $\begin{array}{c}\text { Weight/ } \\
\text { g }\end{array}$ & $\begin{array}{l}\text { Density/ } \\
\text { g. } \mathbf{c m}^{-3}\end{array}$ & $\begin{array}{l}\text { Compressive } \\
\text { strength/MPa }\end{array}$ & $\begin{array}{c}\text { Elastic } \\
\text { modulus/MPa }\end{array}$ \\
\hline $0-1$ & 0 & 47.740 & 101.100 & 263.500 & 1.457 & 10.892 & 1,967 \\
\hline $0-2$ & & 47.547 & 96.373 & 243.000 & 1.421 & 6.759 & 1,591 \\
\hline $0-3$ & & 47.273 & 99.707 & 252.500 & 1.444 & 4.006 & 730.5 \\
\hline $8-1$ & 8 & 47.447 & 98.187 & 262.000 & 1.510 & 42.999 & $2,994.4$ \\
\hline $8-2$ & & 47.460 & 100.500 & 233.000 & 1.311 & 43.252 & 3,672 \\
\hline $8-3$ & & 47.300 & 100.613 & 234.000 & 1.324 & 40.210 & 3,725 \\
\hline $16-1$ & 16 & 47.320 & 100.313 & 271.000 & 1.537 & 61.468 & $3,546.9$ \\
\hline $16-2$ & & 47.220 & 99.147 & 267.000 & 1.539 & 71.395 & $3,659.3$ \\
\hline $16-3$ & & 47.407 & 101.107 & 262.000 & 1.469 & 53.167 & $3,136.9$ \\
\hline $25-1$ & 25 & 47.700 & 93.100 & 240.500 & 1.446 & 70.725 & 3,443 \\
\hline $25-2$ & & 47.340 & 100.147 & 288.000 & 1.635 & 79.217 & 4,402 \\
\hline $25-3$ & & 47.447 & 101.233 & 272.000 & 1.520 & 88.009 & 3,883 \\
\hline
\end{tabular}

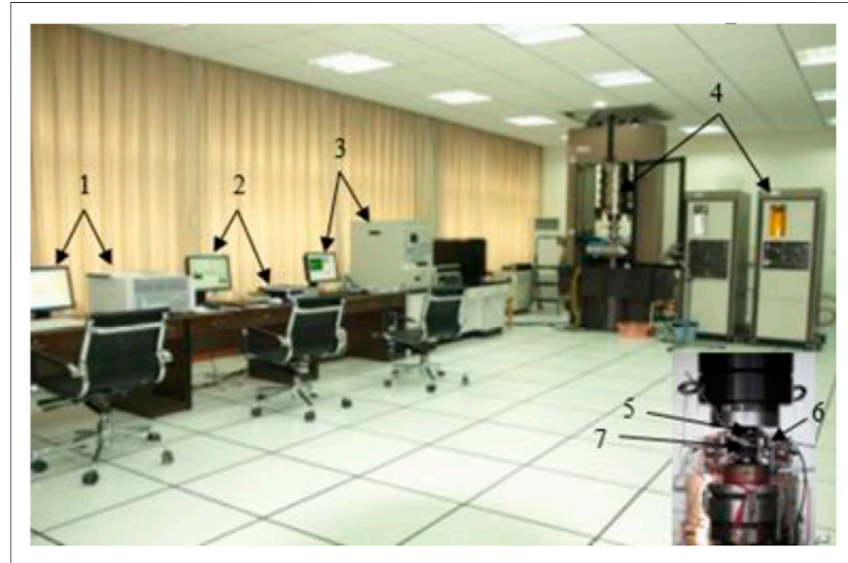

FIGURE 2 | Test system (1, Acoustic emission data acquisition and processing system; 2 , MTS data acquisition and control system; 3, Ultrasonic collecting and processing system; 4, MTS loading system; 5, Acoustic emission probe; 6, Axial extensometer; 7, Transversal extensometer).

coal rocks in Baijiao coal mine mainly contain three elements, carbon, oxygen, and silicon, of which sulfur accounts for $0.8656 \%$ and belongs to sulfur-rich coal rocks. In order to minimize the influence of manual operation on the properties of coal rock, the whole and block coal rock are sampled, and cut and polished uniformly, and the flatness of both end is not more than $0.05 \mathrm{~mm}$. According to the method recommended by the International Society of Rock Mechanics, coal rocks are prepared into $\$ 50 \mathrm{~mm}$ $\times$ L100 mm cylindrical standard specimens (Ulusay, 2015), as shown in Figure 1. Before the test, both ends of the specimen was coated with Vaseline to reduce the influence of inertia effect and end contact friction effect on compression test.

In order to study the effect of confining pressure on the energy dissipation rate of rock, the static compression tests of coal rock under the confining pressures of $0,8,16$, and $25 \mathrm{MPa}$ were carried out. All are loaded with a static strain rate of $10^{-5} \mathrm{~s}^{-1}$. Three repeated tests were carried out under each confining pressure, and a total of 12 tests were conducted. The basic characteristics of the samples are shown in Table 2.

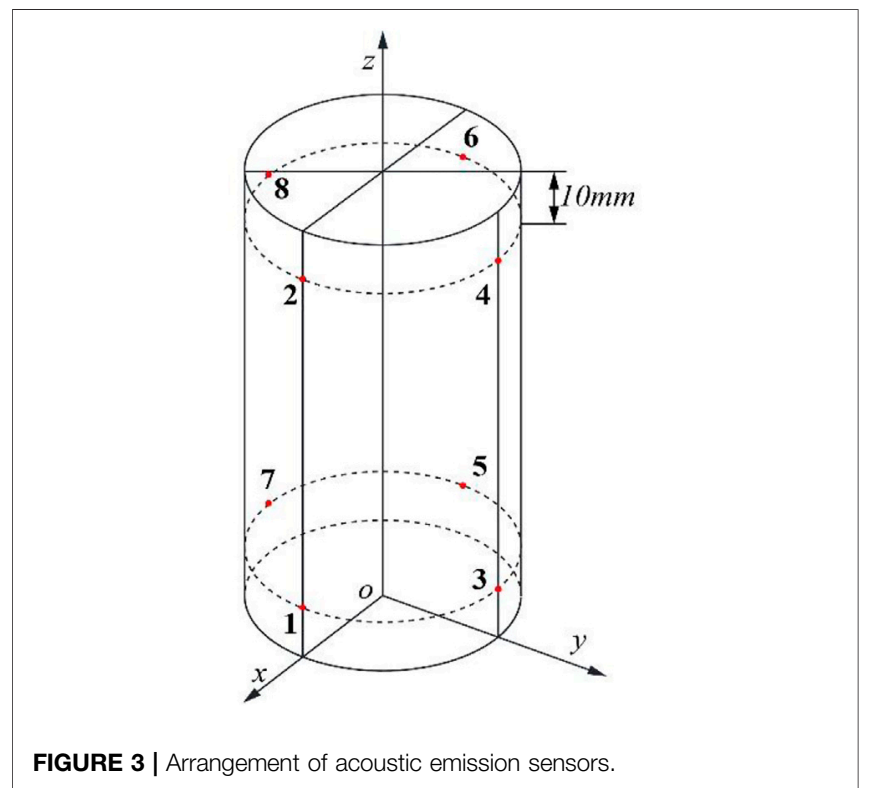

\section{Test System}

The static compression test of coal rock adopts MTS815 rock mechanics test system and equipped with PCI-2 acoustic emission positioning test system, as shown in Figure 2. The strain rate of $10^{-5} \mathrm{~s}^{-1}$ is loaded along the axial direction of the specimen, and it is controlled by LVDT. The PCI-2 acoustic emission positioning test system is equipped with 8 acoustic emission sensors, and the installation position is shown in Figure 3. Considering the low intensity of coal rock and the fast attenuation of acoustic wave, in order to reduce the influence of noise during loading, the threshold value of acoustic emission signal acquisition is set to $40 \mathrm{~dB}$.

\section{Calculation Method of Rock Energy}

According to the Eqs 1-3, the total energy, elastic energy and dissipative energy of coal and rock are calculated (Xie et al., 2005; Xie et al., 2008). 


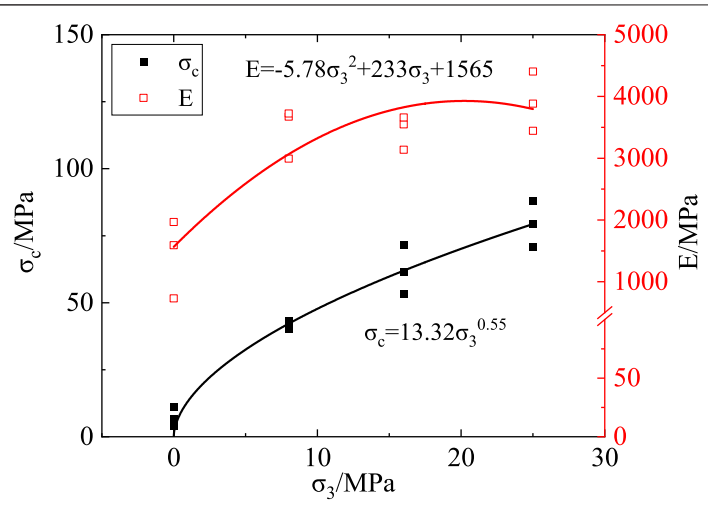

FIGURE 4 | Compressive strength and elastic modulus of coal under different confining pressures.

$$
\begin{gathered}
U(t)=\int_{0}^{\varepsilon_{1}(t)} \sigma_{1}(t) d \varepsilon_{1}(t)+\int_{0}^{\varepsilon_{2}(t)} \sigma_{2}(t) d \varepsilon_{2}(t)+\int_{0}^{\varepsilon_{3}(t)} \sigma_{3}(t) d \varepsilon_{3}(t) \\
U_{e}(t)=\frac{\sigma_{1}(t)^{2}}{2 E_{1}(t)}+\frac{\sigma_{2}(t)^{2}}{2 E_{2}(t)}+\frac{\sigma_{3}(t)^{2}}{2 E_{3}(t)} \\
U_{d}(t)=U(t)-U_{e}(t)
\end{gathered}
$$

where $t$ is the loading time. $U(t)$ is the total energy input by the test system. $U_{e}(t)$ is the elastic energy stored inside coal rock. $U_{d}(t)$ is the dissipative energy in the process of coal rock failure. $\sigma_{i}(t)$ is the stress of coal and rock at any time. $\varepsilon_{i}(t)$ is the strain of coal rock at any time. $E_{i}(t)$ is the elastic modulus of coal rock at any time, and it is regarded as the slope of elastic stage of axial stress-strain curve in this paper; 1 represents axial direction, 2 and 3 both represent circumferential direction.

The energy dissipation rate (EDR) can reflect the process of rock deformation and failure and is calculated by Eq. 4 (Feng et al., 2018).

$$
\delta U_{d}(t)=\frac{\partial U_{d}(t)}{\partial \varepsilon_{1}(t)}
$$

\section{RESULTS}

\section{Analysis of Mechanical Characteristics}

The peak stress of the stress-strain curve is an important physical parameter in engineering application, which is seen as compressive strength. The compressive strength and elastic modulus of coal rock under different confining pressures are shown in Figure 4. From the diagram, it can be seen that with the increase of confining pressure, compressive strength increases exponentially, and the elastic modulus of coal rock increases in a quadratic function. It is not difficult to see that confining pressure significantly enhances the compressive strength and elastic modulus of coal rock. This is because internal fissures of coal rock are closed tightly under the confining pressure, and its deformation and failure are restrained. With the increase of confining pressure, the energy storage limit of coal rock is raised, the bearing capacity is improved obviously, and its ability to resist deformation and failure is also enhanced.

According to the size grades of $0.25,0.5,1.0,5.0,10.0,20.0$, 40.0 , and $50.0 \mathrm{~mm}$, the coal rocks were screened, as shown in Figure 5. From the block after screening, it can be seen that the axial splitting failure of coal rock is dominant under $0 \mathrm{MPa}$, the coal rock fragmentation is more serious, and the medium size coal rock fragment is more. The reason is that coal rock is unconstrained laterally under $0 \mathrm{MPa}$, and the accumulated energy is released laterally under axial load. Therefore, the internal cracks mainly extend in the form of tension cracks, forming the failure mode of axial splitting. With the increase of confining pressure, shear failure mainly occurs in coal rock, and there are larger blocks and more powder rock particles after failure. The higher the confining pressure is, the larger the fragment size is and the more the powder particles are. Under the effect of confining pressure, the internal fissures of coal rock are closed tightly, and the deformation and failure of coal rock are restrained. Under axial compression, coal rocks often slip and friction along the internal weak cementation surface until shear failure. These powder particles are mainly caused by frequent friction on the weak cementation surface.

\section{AE Characteristics}

The propagation and development of internal cracks in coal rock make the energy transfer outside in the form of elastic wave. The acoustic emission information can be monitored and collected during this period. The cumulative number of $\mathrm{AE}$ events and $\mathrm{AE}$ energy of typical coal rocks under different confining pressures are shown in Figure 6. In order to better observe the distribution of $\mathrm{AE}$ at low energy, the breakpoints of some vertical coordinates are processed. As shown in Figure 6, the stress-strain curves can be roughly divided into the compaction stage (OA), the linear elastic stage $(\mathrm{AB})$, the yield stage $(\mathrm{BC})$, and the post-peak failure stage (CD), which is consistent with these references ( $\mathrm{Li}$ et al., 2014; Liu et al., 2020b; Xie et al., 2021). As can be seen from the diagram, AE events seldom occur in the compaction stage and the linear elastic stage. In the yield stage, the $\mathrm{AE}$ events increase slowly and the cracks begin to grow. When the stress increases to a certain extent, the crack propagation speed increases and the $\mathrm{AE}$ activity becomes active. Around the peak stress, the AE activity is particularly intense, often accompanied by high-energy $\mathrm{AE}$ events, which shows that the crack inside the rock has been greatly expanded.

From the distribution of AE in Figure 6, it can be seen that the $\mathrm{AE}$ activity of coal rock under $0 \mathrm{MPa}$ is mainly concentrated in the pre-peak yield stage. With the increase of confining pressure, the $\mathrm{AE}$ activity decreases before the peak stress, and mainly distributes in the post-peak failure stage. The reason is that the deformation and failure of coal rock are restrained under confining pressure, and the internal fissures of coal rock are closed tightly so that they are not easy to expand and develop in the pre-peak stage. After the peak stress, the internal cracks penetrate coal rock, the specimen loses its bearing capacity, and the whole structure suffers severe damage. The crack is easy to expand and develop under the load disturbance. According to the number of accumulated AE events, the total 

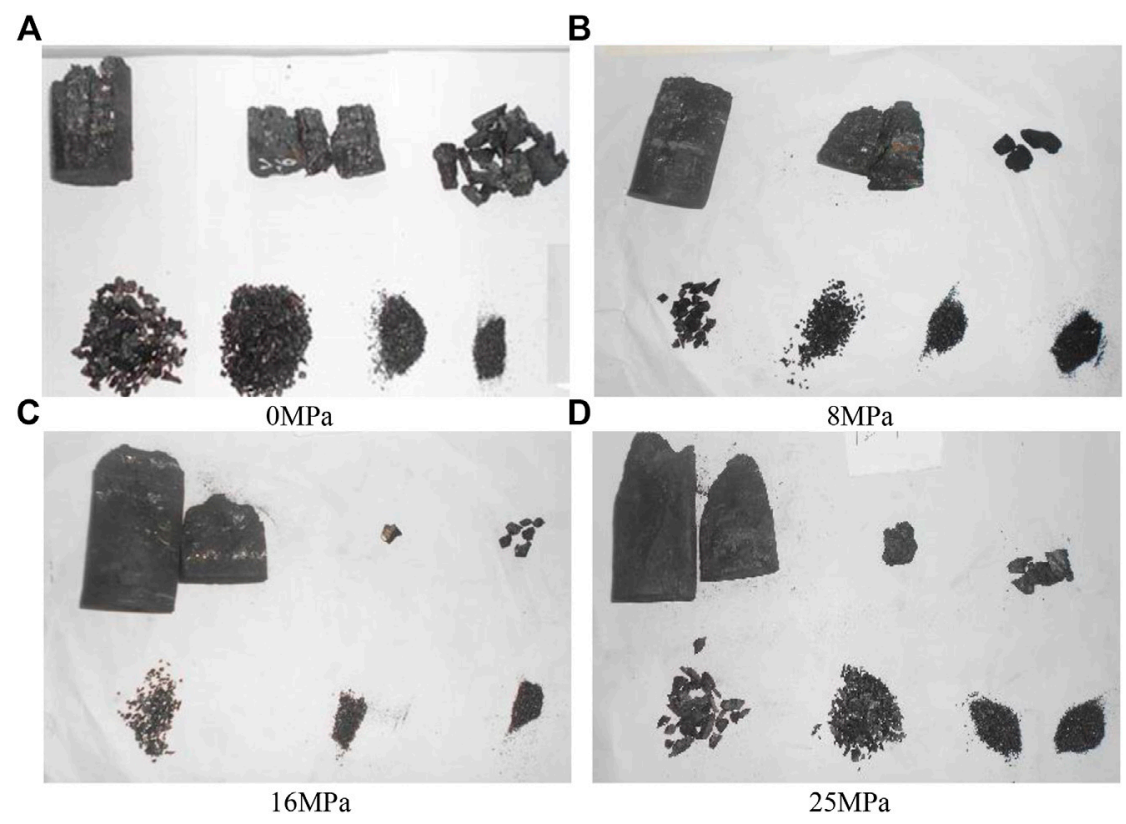

FIGURE 5 | Screen diagram of broken coal-rock block. (A) $0 \mathrm{MPa}$, (B) $8 \mathrm{MPa}$, (C) $16 \mathrm{MPa}$, (D) 25 MPa.

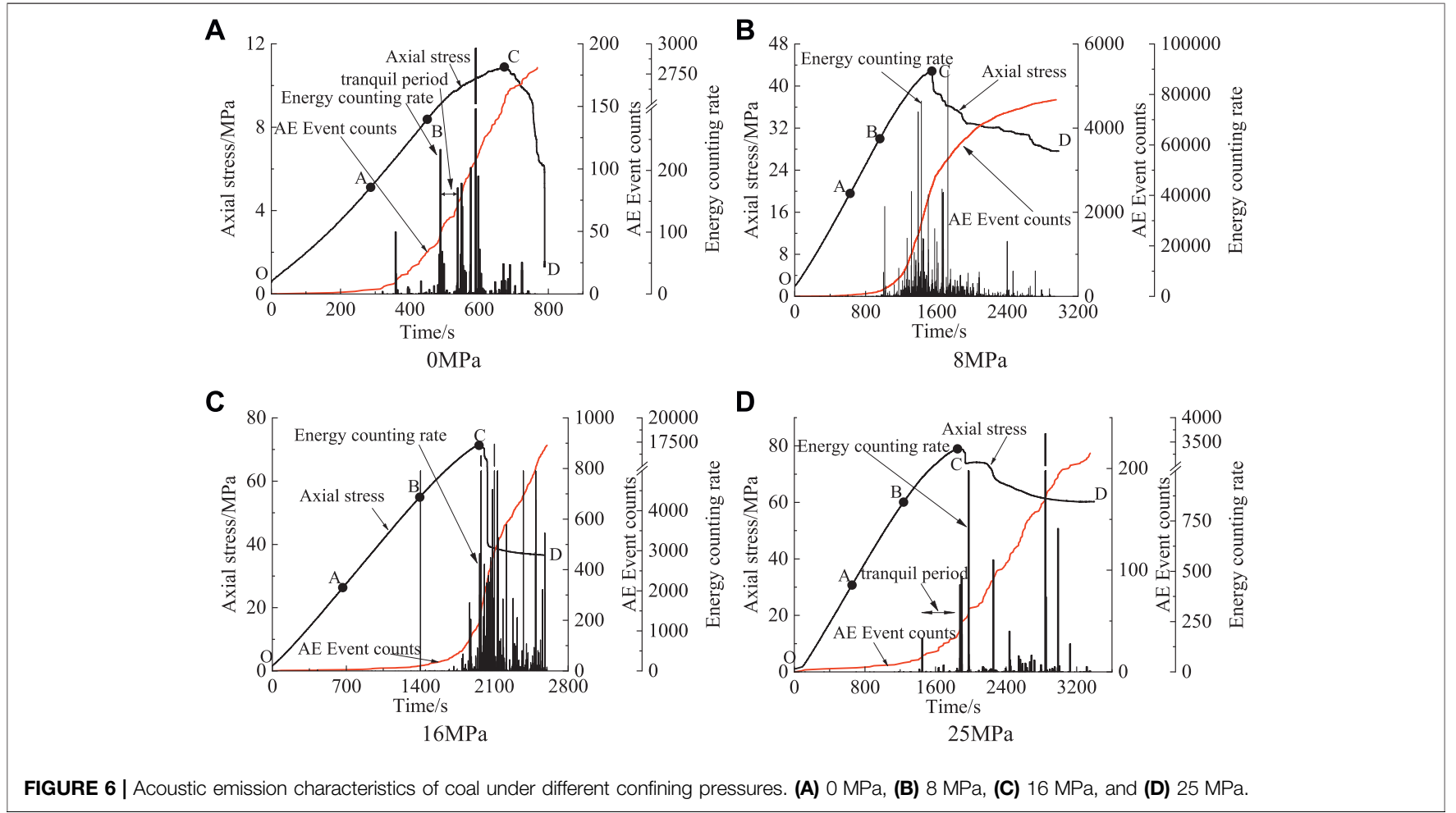

number of AE events of coal rock under $0 \mathrm{MPa}$ is less, so the coal rock is broken into small and medium blocks. The total number of $\mathrm{AE}$ events under triaxial condition is more than that under uniaxial condition. Confined by confining pressure, micro-cracks mainly occur in the slip and friction parts of weak structural plane. Therefore, under the confining pressure, the fine particles of coal rock are more obvious. With the increase of confining pressure, the accumulated number of $\mathrm{AE}$ time and the maximum 

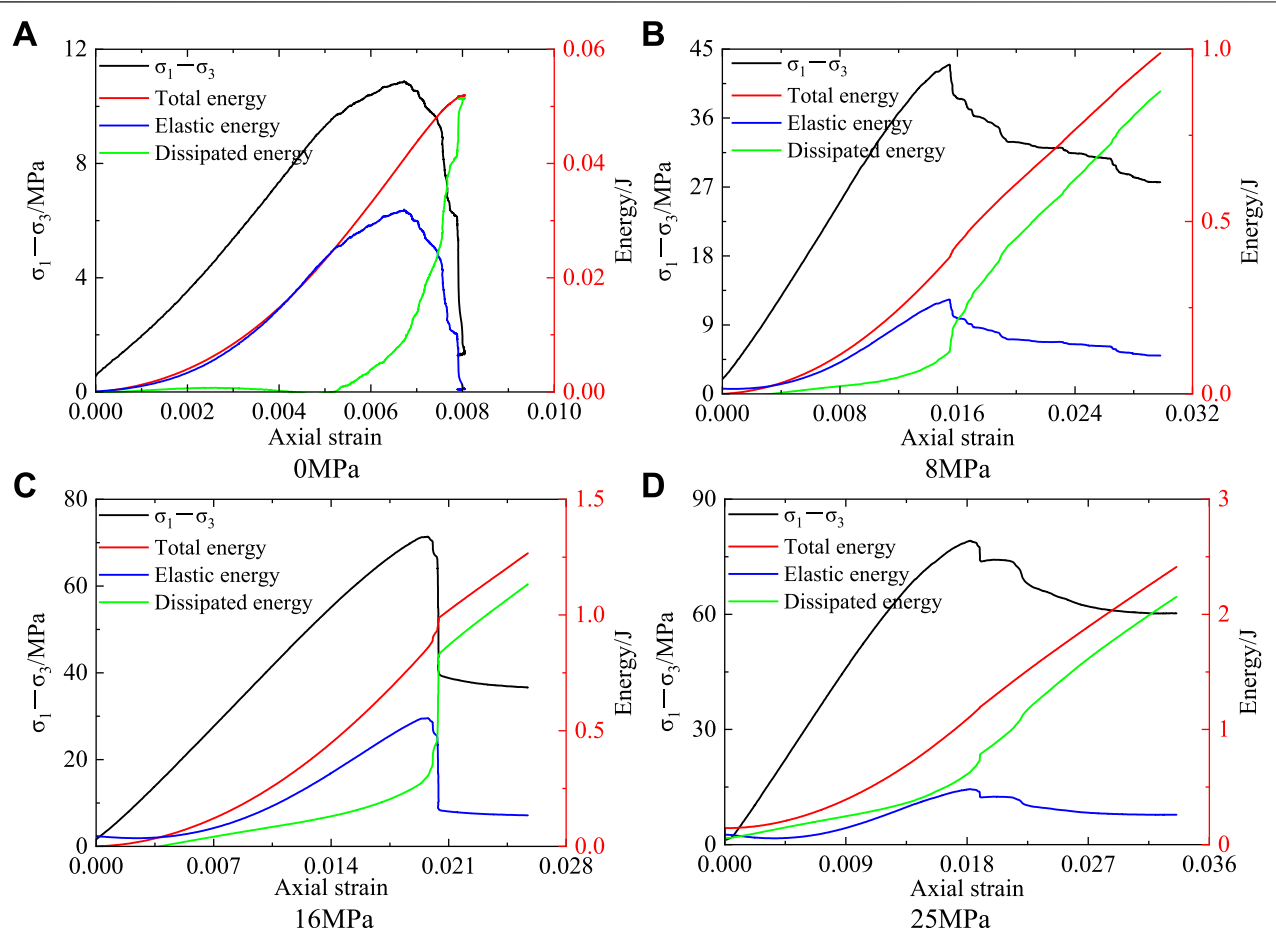

FIGURE 7 | Stress-strain curve and energy evolution process of coal and rock. (A) 0 MPa, (B) 8 MPa, (C) 16 MPa, (D) 25 MPa.

energy of AE decrease obviously, which indicates that confining pressure can restrain the deformation and failure of coal rock obviously.

\section{Law of Energy Evolution}

According to Eqs 1-3, the total input energy, elastic energy, and dissipative energy in the whole process of coal rock failure are calculated, as shown in Figure 7. As can be seen from the diagram, with the increase of confining pressure, the energy level of coal rock obviously increases. With the increase of stress under different confining pressures, the total energy input from outside increases continuously, and the growth rate increases first and then decreases. In the compression stage, the internal cracks and cemented particles of coal rock slip, squeeze and friction under axial load, and the internal cracks of coal rock gradually close. During this period, there will be less acoustic emission activity, less energy dissipation, and elastic energy increases slowly. In the elastic stage, the input energy is stored in the rock mass, and the crack is not expanded, the AE activity is quiet, and the energy of coal rock is not dissipated. When the stress reaches the yield point, the cracks in coal rock begin to initiate, expand, and merge. The $\mathrm{AE}$ activity becomes active, the elastic energy increases slowly, and the dissipated energy increases gradually. When the peak stress is reached, the elastic energy of coal rock reaches the energy storage limit, the crack penetrates rock sample, and energy is released intensely. In the post-peak stage, the joint action of energy release and energy dissipation leads to the continuous development of cracks and the frequent $\mathrm{AE}$ activities, which leads to the aggravation of coal rock damage. The internal elastic energy of coal rock is released continuously, and the dissipation energy is increased continuously. The energy evolution traits are consistent with previous studies (Zhao et al., 2020b; Ma et al., 2021).

The energy characteristic values at the peak stress of coal rock under different confining pressures are shown in Table 3. When the confining pressure increases from 0 to $25 \mathrm{MPa}$, the average values of total energy are $0.028,0.335,0.701$, and $1.251 \mathrm{~J}$, the average values of elastic properties are $0.019,0.225,0.450$, and $0.606 \mathrm{~J}$, and the average dissipation energy values are $0.009,0.111$, 0.252 , and $0.645 \mathrm{~J}$, respectively. It can be seen that with the increase of confining pressure, the total energy, elastic energy, and dissipated energy of coal rock increase greatly. Under the restraining action of confining pressure, the higher the confining pressure, the higher the closure degree of the primary fracture, the stronger the elastic energy accumulation ability, the more difficult the coal rock failure, and the more energy dissipation is needed. It shows that in deep underground engineering, more energy will be released and the damage will be more severe if the rock is damaged catastrophically. As can be seen from Table 3, with the increase of confining pressure level, the difference of dissipated energy of coal rock increases gradually under the same confining pressure, which shows that the crack propagation law is not identical even under the same occurrence environment. The evolution of the crack is mainly determined by the primary defects in coal rock. It is not difficult to see that the failure process of rock under confining pressure cannot be well reflected by a single energy dissipation index. It is necessary to analyze the whole process of energy evolution. In addition, Hou thinks that when the elastic energy and dissipative energy of rock are equal, it can be regarded as the precursor point 
TABLE 3 | Energy characteristics of peak stress of coal rock.

\begin{tabular}{|c|c|c|c|c|c|c|c|c|}
\hline $\begin{array}{l}\text { Serial } \\
\text { number }\end{array}$ & $\begin{array}{c}\text { Confining } \\
\text { pressure/ } \\
\mathrm{MPa}\end{array}$ & $\begin{array}{c}\text { Peak } \\
\text { stress/ } \\
\text { MPa }\end{array}$ & $\begin{array}{c}\text { Total } \\
\text { Energy/J }\end{array}$ & Mean/J & $\begin{array}{c}\text { Elastic } \\
\text { energy/J }\end{array}$ & Mean/J & $\begin{array}{c}\text { Dissipation } \\
\text { energy/J }\end{array}$ & Mean/J \\
\hline $0-1$ & 0 & 10.892 & 0.041 & 0.028 & 0.032 & 0.019 & 0.009 & 0.009 \\
\hline $0-2$ & & 6.759 & 0.024 & & 0.014 & & 0.010 & \\
\hline $0-3$ & & 4.006 & 0.019 & & 0.011 & & 0.008 & \\
\hline $8-1$ & 8 & 42.999 & 0.396 & 0.335 & 0.274 & 0.225 & 0.122 & 0.111 \\
\hline $8-2$ & & 43.252 & 0.326 & & 0.209 & & 0.117 & \\
\hline $8-3$ & & 40.210 & 0.284 & & 0.191 & & 0.094 & \\
\hline $16-1$ & 16 & 61.468 & 0.687 & 0.701 & 0.427 & 0.450 & 0.260 & 0.252 \\
\hline $16-2$ & & 71.395 & 0.857 & & 0.555 & & 0.303 & \\
\hline $16-3$ & & 53.167 & 0.560 & & 0.367 & & 0.193 & \\
\hline $25-1$ & 25 & 70.725 & 1.163 & 1.251 & 0.628 & 0.606 & 0.534 & 0.645 \\
\hline $25-2$ & & 79.217 & 1.113 & & 0.483 & & 0.630 & \\
\hline $25-3$ & & 88.009 & 1.477 & & 0.706 & & 0.771 & \\
\hline
\end{tabular}

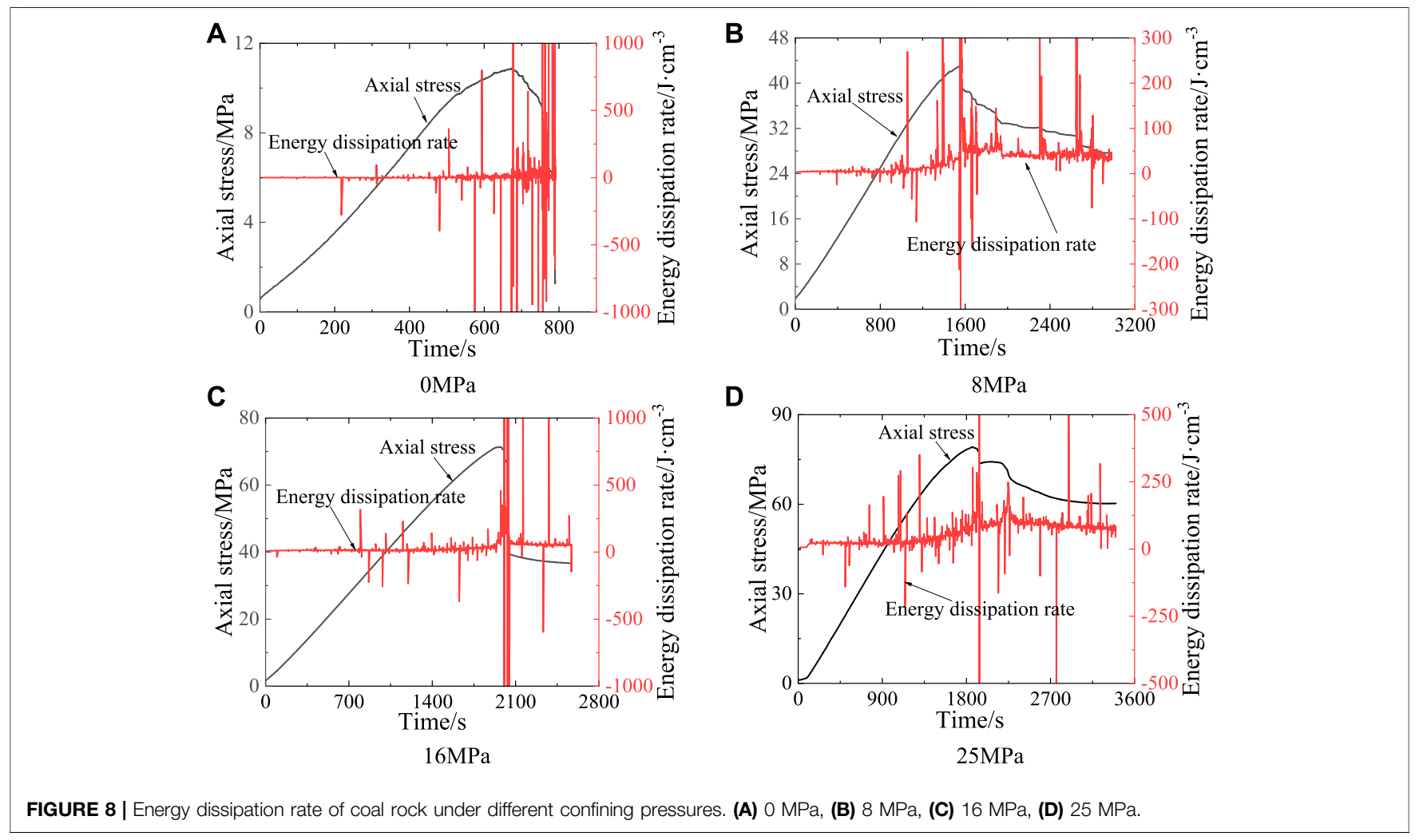

of rock failure (Hou et al., 2021). However, as can be seen from Figure 7, the failure precursor cannot be found at $25 \mathrm{MPa}$. It can also be seen from Table 3 that the energy failure precursors based on the ratio of elastic energy and dissipation energy are not necessarily applicable. Therefore, it is necessary to carry out an indepth study on the damage precursor and put forward more applicable indicators of damage precursor.

\section{Energy Dissipation Rate}

In order to further study the evolution of dissipative energy under different confining pressures, the change rate of dissipative energy relative to axial strain, namely, energy dissipation rate (EDR), is calculated according to Eq. 4. The energy dissipation rate curves of coal rock under different confining pressures are shown in Figure 8. As can be seen from the diagram, the energy dissipation rate is mainly concentrated in the range of $-200-200 \mathrm{~J} \mathrm{~cm}^{-3}$. In the compression stage and elastic stage, little energy dissipation occurs in coal rock, and the fluctuation of energy dissipation rate is relatively quiet. With the increase of stress, the deformation and failure of coal rock increase after entering the plastic stage. The crack is constantly germinating, expanding, and developing. The fluctuation degree of energy dissipation rate increases. Near the 
peak stress, the level of energy dissipation rate will generally increase. After the peak stress, the fluctuation of energy dissipation rate becomes more severe. Especially when the stress drops rapidly, the energy dissipation rate will have a large positive or negative value. This is because the original intact structure of coal rock was seriously damaged, quickly lost the bearing capacity, and suddenly released a large amount of energy when the rock cracks run through at the peak stress. In the post-peak stage, the structure of coal rock was adjusted to a temporary structure with a certain bearing capacity after the dislocation and slippage of coal rock along the internal defective surface, and continued to fail slowly under the action of axial load. It is shown by a slow decrease in stress. As a result, the cracks are more easily developed on the existing defects, and the energy dissipation is strengthened and the energy dissipation rate fluctuates greatly. When the stress of coal rock reaches the residual stage, the fluctuation of energy dissipation rate decreases and remains in a certain range. This is because there are more internal cracks in post-peak than prepeak, and the continuous propagation of cracks will dissipate more energy, which results in higher energy dissipation rate in the residual stage than in the pre-peak stage. Therefore, according to the change law of EDR, the process of rock failure can be roughly divided into a quiet stage, a stable increasing stage, an active stage, and a stable stage.

Before the peak stress, the energy dissipation rate under different confining pressures is mainly kept in a certain range, and the fluctuation range is small. The EDR was maintained in the range of $0.1-7 \mathrm{~J} \mathrm{~cm}^{-3}$ at $0 \mathrm{MPa}, 3-10 \mathrm{~J} \mathrm{~cm}^{-3}$ at $8 \mathrm{MPa}$, $10-20 \mathrm{~J} \mathrm{~cm}^{-3}$ at $16 \mathrm{MPa}$, and $20-40 \mathrm{~J} \mathrm{~cm}^{-3}$ at $25 \mathrm{MPa}$. It is not difficult to see that with the increase of confining pressure, the level of energy dissipation rate before the peak stress has increased obviously. The reason is that the deformation and failure of surrounding rock is restrained by confining pressure. The larger the confining pressure is, the stronger the confining effect is. When energy is the same, the slow increase of strain makes energy dissipation rate increase. In addition, the fluctuation range of the energy dissipation rate shows that with the increase of confining pressure, the fluctuation of the peak energy dissipation rate increases, but the level of energy dissipation rate is not high. It is shown that the increase of confining pressure enhances the microcrack growth before the peak stress. With the increase of confining pressure, the fluctuation of energy dissipation rate becomes more frequent and the level of energy dissipation rate is higher in the post-peak failure stage. The results show that the increase of confining pressure makes the damage of coal rock more serious in the postpeak stage, and the main reason is the passing of local cracks.

\section{DISCUSSION}

\section{Relationship Between Energy Dissipation Rate and Crack Propagation}

From the above analysis of acoustic emission, it can be seen that the acoustic emission information reflects the characteristics of rock damage evolution. However, the acoustic emission information collected by acoustic emission (AE) acquisition equipment will be seriously disturbed by the noise in the practical rock engineering. The crack propagation and damage evolution in the process of rock failure are discussed from the view of energy, which is closer to the essence of rock failure. In order to study the relationship between the energy dissipation rate and the crack propagation, the energy dissipation rate is compared with the acoustic emission information.

The relationship between the energy dissipation rate and the number of $\mathrm{AE}$ events during rock failure under different confining pressures is shown in Figure 9. In the diagram, the blue circles show where the $\mathrm{AE}$ increases rapidly, and the black circles show where the stress decreases rapidly. From the diagram, it can be seen that the energy dissipation rate in the local area before the peak stress suddenly increases or drops to form a peak value. At the same time, the number of AE events increases rapidly, which indicates that the crack inside the coal rock grows rapidly at the peak value of the energy dissipation rate, causing damage to coal rock. In the poststress stage, the frequency of the EDR peak value increases obviously, and the position of the EDR peak value is relatively concentrated and it is relatively large. The corresponding stress often drops suddenly, and the number of AE events increases obviously, which indicates that the crack propagation degree is high and even penetrates the rock sample. In the process of rock failure, the crack development is usually caused by the tensile crack tip, which extends along the crack surface and produces a new crack. Under $0 \mathrm{MPa}$ confining pressure, the axial tension crack is the main crack. The specimen deforms in lateral direction under axial pressure and forms axial splitting failure. Rock is prone to sudden stress drop and complete loss of bearing capacity. With the increase of confining pressure, the limiting effect of confining pressure on the lateral deformation of rock increases, and the crack develops into a large shear crack. After the shear crack runs through, the coal rock block slips along the crack to form the shear failure surface, which leads to the sudden drop of stress. These sudden stress drops are caused by the propagation of micro-cracks into macro-fracture surfaces. The more obvious the stress drop is, the greater the crack propagation degree is, and the more energy is dissipated, so the energy dissipation rate is higher when stress drops. In a word, the peak value of energy dissipation rate is caused by crack propagation. It is reliable and universal to use energy dissipation rate to evaluate crack propagation and damage evolution in coal rock.

\section{Failure Precursor Based on Energy Dissipation Rate}

Acoustic emission (AE) technique is the most commonly used method to study the precursors of rock failure. As can be seen from Figure 9, the sudden increase in the number of AE events indicates that the extent range of crack propagation is wide, which can be regarded as the precursor of coal rock failure. However, before the peak stress, there are many sudden increase points of 

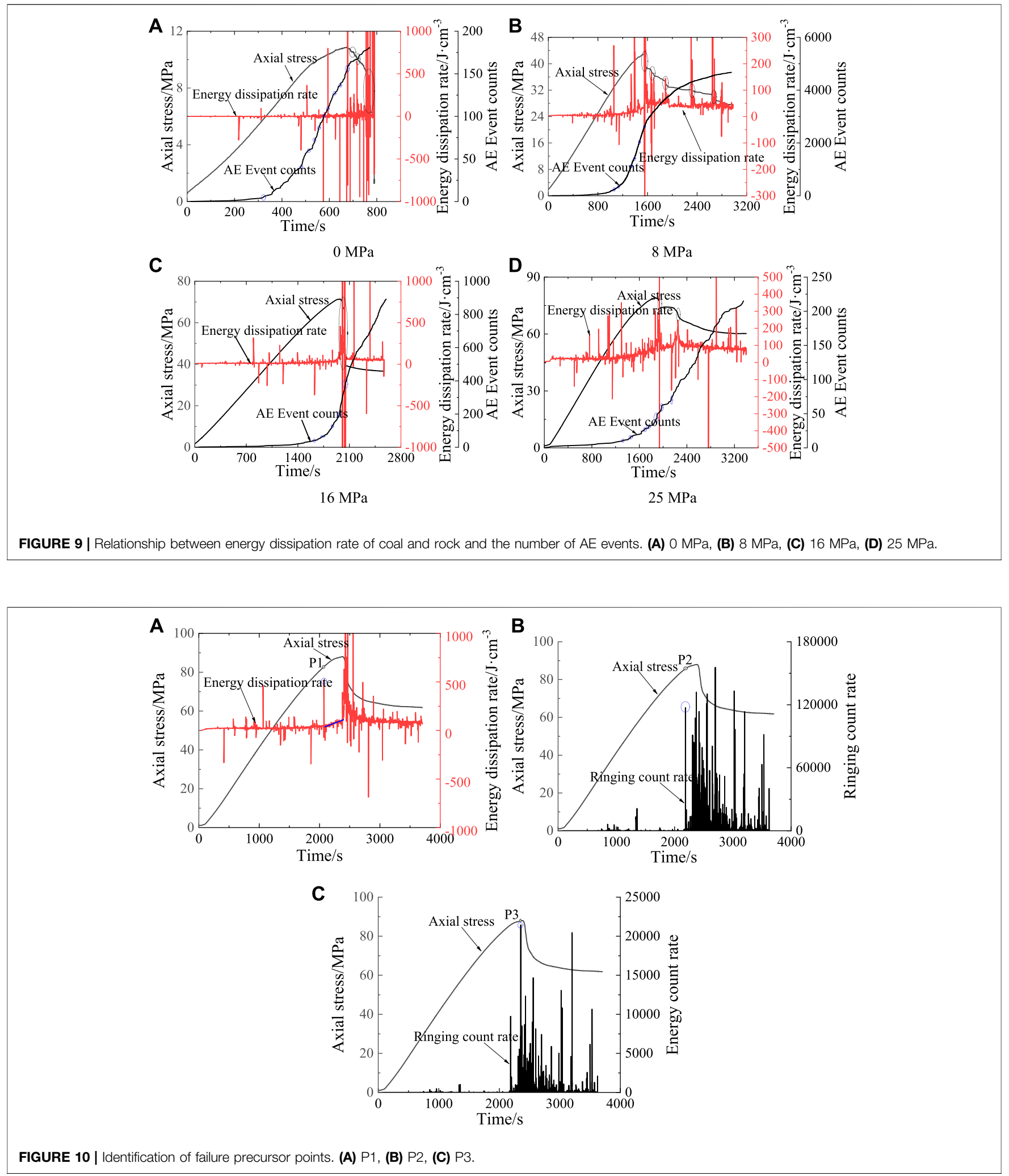

$\mathrm{AE}$ counting, and the determination of damage precursor point is not clear enough. In addition, as shown in Figures 6A,D, there is an obvious quiet period of $\mathrm{AE}$ activity before peak stress, which can be used as a precursor of rock failure. These quiet periods do not mean the stability of the rock, but indicate that the rock is about to be destroyed (Zhang et al., 2006). However, in Figures 

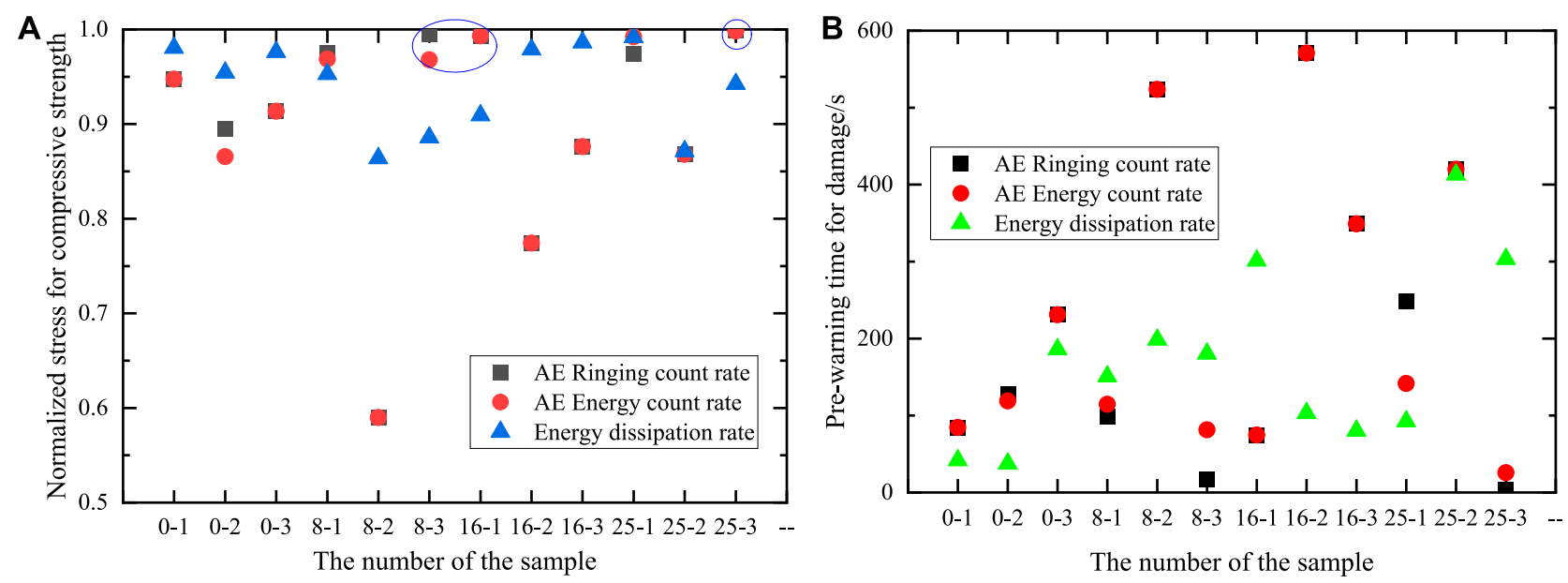

FIGURE 11 | Comparison of failure precursor features. (A) Normalized stress of compressive strength, (B) Pre-warning time of damage.

6B,C, the quiet phase of $\mathrm{AE}$ is difficult to distinguish. In the actual project monitoring, the researchers also found that the corresponding relationship between disasters and the quiet period of $\mathrm{AE}$ is not obvious in time (Li et al., 2019). It can be seen that the engineering results are similar to the experimental results, which shows that the applicability of AE quiet period as a precursor of rock failure is questionable. Some scholars have proposed that the counting of $\mathrm{AE}$ events or the sudden increase of energy can be regarded as the characteristic of failure. However, in most cases, this sudden increase occurs at the peak stress, and after the peak stress, the early warning for rock disaster is put off because the requirements of early warning are not met (Li et al., 2019). It can be seen that there are still some deficiencies in monitoring rock stability by acoustic emission technology. Considering the influence of engineering environment noise on acoustic emission monitoring equipment, it is more practical to propose an energy failure precursor of rock failure from the view of energy.

According to the evolution law of energy dissipation rate under different confining pressures, it is found that the energy dissipation rate has a stable increasing stage before reaching the peak stress, which indicates an impending failure of the rock, as shown by the blue diagonal in Figure 10A. Therefore, taking a sample as an example, the last peak of energy dissipation rate before the level of energy dissipation rate rises is proposed as the failure precursor, where the peak of energy dissipation rate corresponds to the stress value of P1, as shown in Figure 10A. In order to verify the accuracy and practicability of rock failure energy precursor P1, it is compared with acoustic emission failure precursor. $\mathrm{Li}$ proposed that the peak value of $\mathrm{AE}$ ringing count rate and $\mathrm{AE}$ energy count rate before peak stress should be regarded as the precursory characteristics of rock failure, which can effectively give an early warning of rock failure (Li et al., 2016). The maximum values of $\mathrm{AE}$ ringing count rate and $\mathrm{AE}$ energy count rate before peak stress are $\mathrm{P} 2$ and $\mathrm{P} 3$ respectively, as shown in Figures 10B,C.
For the convenience of comparison, P1, P2, and P3 are divided by compressive strength and normalized. The closer the normalized value of stress is to 1 , the closer the failure precursor of the peak stress and the faster the failure of rock occurs. The normalized values of stress at the rock failure precursor points under different confining pressures are shown in Figure 11A. It can be found that the failure precursor points based on $\mathrm{AE}$ energy counting rate and $\mathrm{AE}$ ringing counting rate are very close, and some samples appear almost at the same time, which is basically consistent with previous studies (Li et al., 2016). The normalized value of $\mathrm{P} 2$ determined by $\mathrm{AE}$ ringing count in samples $8-3,16-1$, and $25-3$ is over 0.99 , and the failure precursor point is very close to the peak stress. This may lead to shorter warning time; the actual project engineers do not have enough time to take the corresponding rock disaster prevention measures. In addition, the corresponding stress values of P2 and P3 in samples 8-2 and 16-2 are small, which may be too safe. Based on the energy dissipation rate, the stress normalization values of the failure precursor P1 are in the range of 0.85-0.99. Generally speaking, the stress normalization values of $\mathrm{P} 1$ are larger than those of P2 and P3. The early warning time for rock failure is obtained by subtracting the corresponding moments of P1, P2, and P3 from the time of peak stress, as shown in Figure 11B. On the whole, the early warning time based on energy dissipation rate is longer than that based on acoustic emission. The minimum warning time of $\mathrm{P} 1$ is $37.5 \mathrm{~s}$ under different confining pressures, and it shows that the failure precursor points determined based on the energy dissipation rate can reserve enough time for the early warning and prevention of rock disasters. With the increase of confining pressure, the time of P1 early warning increased. It is not difficult to see that the above-mentioned characteristics of the energy failure precursors fully show that the rock failure precursors determined by the energy dissipation rate have better reliability and universality, and it can provide a reference value for the prevention and control of underground rock dynamic disasters such as rock burst. 


\section{CONCLUSION}

In this paper, the static compression tests and acoustic emission location tests $(\mathrm{AE})$ of coal rocks were carried out under different confining pressures. Based on the analysis of rock energy evolution, the characteristics of energy dissipation rate (EDR) under different confining pressures were emphatically discussed. The main conclusions were obtained as follows:

(1) Confining pressure effect is better reflected in the mechanical, $\mathrm{AE}$, and energy properties of coal rock. With an increase in confining pressure, the increasing trend of elastic modulus and compressive strength is found. The deformation and failure of coal rock are restrained. Correspondingly, the total energy, elastic energy, and dissipative energy are obviously improved.

(2) The variation of EDR can be roughly divided into a quiet stage, a stable increasing stage, an active stage, and a stable stage. The EDR level remains in a low range in pre-peak and increases with an increase in confining pressure. The EDR increases gradually near the peak stress and fluctuates sharply after the peak stress.

(3) The EDR can be used as an internal index to evaluate the crack propagation in rock. When the EDR increased or decreased suddenly, the acoustic emission events increased rapidly. When the peak value of EDR fluctuates greatly and concentrates in the post-peak period, the internal fissures will penetrate rock causing a sudden stress drop.

(4) A new energy precursor point of rock failure is proposed based on the EDR. The stress level of EDR precursor point is

\section{REFERENCES}

Ai, T., Zhang, R., Liu, J. F., Zhao, X. P., and Ren, L. (2011). Space-time Evolution Rules of Acoustic Emission Locations Under Triaxial Compression. J. China Coal Soc. 36 (12), 2048-2057. doi:10.13225/j.cnki.jccs.2011.12.019

Cai, W., Dou, L., Cao, A., Gong, S., and Li, Z. (2014). Application of Seismic Velocity Tomography in Underground Coal Mines: A Case Study of Yima Mining Area, Henan, China. J. Appl. Geophys. 109, 140-149. doi:10.1016/j. jappgeo.2014.07.021

Du, K., Li, X., Tao, M., and Wang, S. (2020). Experimental Study on Acoustic Emission (AE) Characteristics and Crack Classification During Rock Fracture in Several Basic Lab Tests. Int. J. Rock Mech. Mining Sci. 133, 104411. doi:10. 1016/j.ijrmms.2020.104411

Feng, J., Wang, E., Chen, X., and Ding, H. (2018). Energy Dissipation Rate: An Indicator of Coal Deformation and Failure under Static and Dynamic Compressive Loads. Int. J. Mining Sci. Technology. 28, 397-406. doi:10.1016/ j.ijmst.2017.11.006

Gao, L., Gao, F., Zhang, Z., and Xing, Y. (2020). Research on the Energy Evolution Characteristics and the Failure Intensity of Rocks. Int. J. Mining Sci. Technology. 30, 705-713. doi:10.1016/j.ijmst.2020.06.006

Gao, M., Xie, J., Gao, Y., Wang, W., Li, C., Yang, B., et al. (2021a). Mechanical Behavior of Coal under Different Mining Rates: A Case Study from Laboratory Experiments to Field Testing. Int. J. Mining Sci. Technology. 31, 825-841. doi:10.1016/j.ijmst.2021.06.007

Gao, M., Xie, J., Guo, J., Lu, Y., He, Z., and Li, C. (2021b). Fractal Evolution and Connectivity Characteristics of Mining-Induced Crack Networks in Coal Masses at Different Depths. Geomech. Geophys. Geo-energ. Geo-resour. 7 (1), 1-15. doi:10.1007/s40948-020-00207-4 higher and occurs later than the $\mathrm{AE}$ precursor point. It indicates that energy failure precursor can provide a reference value for the prevention of rock disasters such as rock burst.

\section{DATA AVAILABILITY STATEMENT}

The original contributions presented in the study are included in the article/supplementary material. Further inquiries can be directed to the corresponding author.

\section{AUTHOR CONTRIBUTIONS}

$\mathrm{XL}$ and YX designed the research. YX processed the corresponding data. YX wrote the first draft of the manuscript. $\mathrm{YZ}$ and HL helped to organize the manuscript. XL revised the final version.

\section{FUNDING}

This research is financially supported by the Opening Fund of Key Laboratory of Deep Earth Science and Engineering Ministry of Education of Sichuan University (Grant No. DESE202003), the Key Scientific Research Fund of Xihua University (Grant No. Z17113), and the Research Center for Social Development and Social Risk Control of Sichuan Province, Key Research Base of Philosophy and Social Sciences, Sichuan University (No. SR21A04).

Gong, F., Wang, Y., Wang, Z., Pan, J., and Luo, S. (2021). A New Criterion of Coal Burst Proneness Based on the Residual Elastic Energy index. Int. J. Mining Sci. Technology. 31, 553-563. doi:10.1016/j.ijmst.2021.04.001

Gong, F., Yan, J., Li, X., and Luo, S. (2019). A Peak-Strength Strain Energy Storage Index for Rock Burst Proneness of Rock Materials. Int. J. Rock Mech. Mining Sci. 117, 76-89. doi:10.1016/j.ijrmms.2019.03.020

Guo, T. Y., and Wong, L. N. Y. (2020). Microcracking Behavior of Three Granites under Mode I Loading: Insights from Acoustic Emission. Eng. Geology. 278, 105823. doi:10.1016/j.enggeo.2020.105823

He, J., Dou, L., Gong, S., Li, J., and Ma, Z. (2017). Rock Burst Assessment and Prediction by Dynamic and Static Stress Analysis Based on Micro-Seismic Monitoring. Int. J. Rock Mech. Mining Sci. 93, 46-53. doi:10.1016/j.ijrmms. 2017.01.005

Hou, Y., Yin, S., Chen, X., Zhang, M., and Yang, S. (2021). Study on Characteristic Stress and Energy Damage Evolution Mechanism of Cemented Tailings Backfill Under Uniaxial Compression. Construction Building Mater. 301, 124333. doi:10.1016/j.conbuildmat.2021.124333

Jiang, Y., Zhao, Y., Wang, H., and Zhu, J. (2017). A Review of Mechanism and Prevention Technologies of Coal Bumps in China. J. Rock Mech. Geotechnical Eng. 9, 180-194. doi:10.1016/j.jrmge.2016.05.008

Junthong, P., Khamrat, S., Sartkaew, S., and Fuenkajorn, K. (2019). Determination of Time-Dependent Strengths of Salt Pillars Based on Strain Energy Principle. Int. J. Mining Sci. Technology. 29, 273-279. doi:10.1016/j.ijmst.2018.04.011

Li, A. Q., Zhang, R., Ai, T., Gao, M. Z., Zhang, Z. T., Liu, Q. Y., et al. (2016). Acoustic Emission Space-Time Evolution Rules and Failure Precursors of Granite under Uniaxial Compression. Chin. J. Geotech. Eng. 38 (S2), 306-311. doi:10.11779/CJGE2016S2050

Li, D., Wang, E., Kong, X., Ali, M., and Wang, D. (2019). Mechanical Behaviors and Acoustic Emission Fractal Characteristics of Coal Specimens with a Pre- 
Existing Flaw of Various Inclinations Under Uniaxial Compression. Int. J. Rock Mech. Mining Sci. 116, 38-51. doi:10.1016/j.ijrmms.2019.03.022

Li, Y., Huang, D., and Li, X. a. (2014). Strain Rate Dependency of Coarse crystal marble under Uniaxial Compression: Strength, Deformation and Strain Energy. Rock Mech. Rock Eng. 47, 1153-1164. doi:10.1007/s00603-013-0472-x

Liu, X., Hao, Q. J., Hu, A. K., and Zheng, Y. (2020a). Study on Determination of Uniaxial Characteristic Stress of Coal Rock under Quasi-Static Strain Rate. Chin. J. Rock Mech. Eng. 39 (10), 2038-2046. doi:10.13722/j.cnki.jrme.2020. 0321

Liu, X., Liu, Z., Li, X., Gong, F., and Du, K. (2020b). Experimental Study on the Effect of Strain Rate on Rock Acoustic Emission Characteristics. Int. J. Rock Mech. Mining Sci. 133, 104420. doi:10.1016/j.ijrmms.2020.104420

Liu, X., Zhao, X. P., and Liu, J. F. (2014). A Study on the Acoustic Emission Characteristics of the Coal Rock on Different Bedding Direction. Comput. Model. New Technol. 18 (5), 308-313.

Ma, S., Chen, W., and Zhao, W. (2021). Effects of Axial Static Stress and Confining Pressure on the Dynamic Compressive Behaviours of Granite. Eur. J. Environ. Civil Eng. 25 (5), 795-812. doi:10.1080/19648189.2018.1547665

Qin, Z., Li, T., Li, Q., Chen, G., and Cao, B. (2019). Combined Early Warning Method for Rock Burst and its Engineering Application. Adv. Civil Eng. 2019, 1-10. doi:10.1155/2019/1269537

Si, X., and Gong, F. (2020). Strength-weakening Effect and Shear-Tension Failure Mode Transformation Mechanism of Rockburst for Fine-Grained Granite under Triaxial Unloading Compression. Int. J. Rock Mech. Mining Sci. 131, 104347. doi:10.1016/j.ijrmms.2020.104347

Tian, B. Z., Liu, S. J., Zhang, Y. B., Liang, P., and Liu, X. X. (2016). Laboratory Simulation of Temporospatial Evolution Characteristics of Infrared Radiation in the Process of Rockburst in Granite Tunnel. Rock Soil Mech. 37 (3), 711-718. doi:10.16285/j.rsm.2016.03.013

Ulusay, R. (2015). The ISRM Suggested Methods for Rock Characterization. Germany: Testing and Monitoring: 2007-2014. doi:10.1007/978-3-31907713-0

Wang, C., Si, G., Zhang, C., Cao, A., and Canbulat, I. (2021). Location Error Based Seismic Cluster Analysis and its Application to Burst Damage Assessment in Underground Coal Mines. Int. J. Rock Mech. Mining Sci. 143, 104784. doi:10. 1016/j.ijrmms.2021.104784

Xie, H., Li, C., He, Z., Li, C., Lu, Y., Zhang, R., et al. (2021). Experimental Study on Rock Mechanical Behavior Retaining the In Situ Geological Conditions at Different Depths. Int. J. Rock Mech. Mining Sci. 138, 104548. doi:10.1016/j. ijrmms.2020.104548

Xie, H. p., Ju, Y., and Li, L. Y. (2005). Criteria for Strength and Structural Failure of Rocks Based on Energy Dissipation and Energy Release Principles. Chin. J. Rock Mech. Eng. 24 (17), 3003-3010. doi:10.3321/j.issn:1000-6915.2005.17.001

Xie, H. P., Ju, Y., Li, L. Y., and Peng, R. D. (2008). Energy Mechanism of Deformation and Failure of Rock Masses. Chin. J. Rock Mech. Eng. 27 (9), 1729-1740. doi:10.3321/j.issn:1000-6915.2008.09.001

Xu, X. D., Sun, G. H., Yao, X. L., Liang, X. J., and Shao, L. H. (2020). A Cusp Catastrophe Warning Model for Instability of Backfill Based on Energy Dissipation and Release. Rock Soil Mech. 41 (9), 3003-3012. doi:10.16285/j. rsm.2019.1475

Yang, S.-Q., Chen, M., Huang, Y.-H., Jing, H.-W., and Ranjith, P. G. (2020). An Experimental Study on Fracture Evolution Mechanism of a Non-persistent Jointed Rock Mass with Various anchorage Effects by DSCM, AE and X-ray CT
Observations. Int. J. Rock Mech. Mining Sci. 134, 104469. doi:10.1016/j.ijrmms. 2020.104469

Yaodong, J., Hongwei, W., Yixin, Z., Jie, Z., and Xufeng, P. (2011). The Influence of Roadway Backfill on Bursting Liability and Strength of Coal Pillar by Numerical Investigation. Proced. Eng. 26, 1125-1143. doi:10.1016/j.proeng.2011.11.2283

Zhang, C., Canbulat, I., Hebblewhite, B., and Ward, C. R. (2017). Assessing Coal Burst Phenomena in Mining and Insights into Directions for Future Research. Int. J. Coal Geology. 179, 28-44. doi:10.1016/j.coal.2017.05.011

Zhang, R., Xie, H. P., Liu, J. F., Deng, J. H., and Peng, Q. (2006). Experimental Study on Acoustic Emission Characteristics of Rock Failure under Uniaxial Multilevel Loadings. Chin. J. Rock Mech. Eng. 25 (12), 2584-2588. doi:10.3321/j.issn:10006915.2006.12.028

Zhao, G. y., Dai, B., Dong, L.-j., and Yang, C. (2015). Energy Conversion of Rocks in Process of Unloading Confining Pressure under Different Unloading Paths. Trans. Nonferrous Met. Soc. China. 25, 1626-1632. doi:10.1016/S1003-6326(15) 63767-0

Zhao, K., Yang, D., Gong, C., Zhuo, Y., Wang, X., and Zhong, W. (2020a). Evaluation of Internal Microcrack Evolution in Red Sandstone Based on Time-Frequency Domain Characteristics of Acoustic Emission Signals. Construction Building Mater. 260, 120435. doi:10.1016/j.conbuildmat.2020.120435

Zhao, K., Yu, X., Zhou, Y., Wang, Q., Wang, J., and Hao, J. (2020b). Energy Evolution of Brittle Granite under Different Loading Rates. Int. J. Rock Mech. Mining Sci. 132, 104392. doi:10.1016/j.ijrmms.2020.104392

Zhou, C. H., Li, Y. A., Yin, J. M., Wang, Y., and Zhou, C. (2019). Study on the Characteristics of Microseismicity and Electromagnetic Radiation Activity of the Underground Powerhouse at Huanggou Pumped Storage Power Station Subjected to the Excavation. Chin. J. Rock Mech. Eng. 38 (S2), 3583-3594. doi:10.13722/j.cnki.jrme.2019.0618

Zhou, C. H., Li, Y. A., Yin, J. M., Wang, Y., Zhou, C., and Guo, X. F. (2020). Multivariate Early Warning Method for Rockbursts Based on Comprehensive Microseismic and Electromagnetic Radiation Monitoring. Chin. J. Geotech. Eng. 42 (3), 457-466. doi:10.11779/CJGE202003007

Zhou, Z., Cai, X., Li, X., Cao, W., and Du, X. (2020). Dynamic Response and Energy Evolution of Sandstone Under Coupled Static-Dynamic Compression: Insights from Experimental Study into Deep Rock Engineering Applications. Rock Mech. Rock Eng. 53, 1305-1331. doi:10.1007/s00603-019-01980-9

Conflict of Interest: The authors declare that the research was conducted in the absence of any commercial or financial relationships that could be construed as a potential conflict of interest.

Publisher's Note: All claims expressed in this article are solely those of the authors and do not necessarily represent those of their affiliated organizations, or those of the publisher, the editors and the reviewers. Any product that may be evaluated in this article, or claim that may be made by its manufacturer, is not guaranteed or endorsed by the publisher.

Copyright $\odot 2022 \mathrm{Liu}, \mathrm{Xue}$, Zheng and Li. This is an open-access article distributed under the terms of the Creative Commons Attribution License (CC BY). The use, distribution or reproduction in other forums is permitted, provided the original author(s) and the copyright owner(s) are credited and that the original publication in this journal is cited, in accordance with accepted academic practice. No use, distribution or reproduction is permitted which does not comply with these terms. 